\title{
Clinical anatomy of the anterior cruciate ligament and pre-operative prediction of ligament length
}

\author{
Mrs R van Zyl, ${ }^{1,2}$ MSc Anatomy \\ Dr A-N van Schoor, ${ }^{2}$ PhD Anatomy \\ Dr PJ du Toit, ${ }^{3}$ PhD Physiology \\ Dr EM Louw, ${ }^{4}$ PhD Statistics
}

${ }^{1}$ Lecturer, Department of Basic Medical Sciences, School of Medicine, Faculty of Health Sciences,

University of Free State, South Africa

${ }^{2}$ Senior lecturer, Department of Anatomy, School of Medicine, Faculty of Health Sciences, University of Pretoria, South Africa

${ }^{3}$ Professor, Department of Physiology, School of Medicine, Faculty of Health Sciences,

Associate of the Institute for Food, Nutrition and Well-being, Associate of the Institute for Cellular and Molecular Medicine, Associate of the Exercise Smart Team, University of Pretoria, South Africa

${ }^{4}$ Senior lecturer, Department of Statistics, Faculty of Natural and Agricultural Sciences, University of Pretoria, South Africa

\author{
Corresponding author: \\ Mrs Reinette van Zyl \\ Department of Basic Medical Sciences (G25) \\ Faculty of Health Sciences \\ University of Free State \\ PO Box 339 \\ Bloemfontein, 9300, \\ South Africa. \\ Tel: $+27(0) 514017362$ \\ Fax: +27 (0)51 4019134 \\ Email: ebersohnr@ufs.ac.za
}

\begin{abstract}
Background: Ligament grafts used in anterior cruciate ligament (ACL) reconstruction need to be the correct length for proper functioning. If the graft length is incorrect, the patient could risk knee instability, loss of range of motion, or failure of graft fixation. Easier and time-efficient reconstruction will be facilitated if the length of the ACL is predicted in advance.

Apart from examining the morphological properties of the ACL, this study aimed to determine whether the epicondylar width of an individual can be used to predict ACL length and thereby assist in restoring the normal anatomy of the ACL.

Methods: Ninety-one adult cadavers were studied. Patellar ligament (PL) length, ACL length, ACL width and the maximum femoral epicondylar width (FECW) were measured.

Results: The morphology of the ACL and PL was determined. The results revealed that FECW was the most reliable predictor of ACL length. A linear regression formula was developed in order to determine ACL length by measuring maximum FECW.

Conclusions: ACL and PL morphology compared well with the results found in previous studies. An individual's FECW can be used to predict ACL length pre-operatively. These results could improve pre-operative planning of ACL reconstruction.
\end{abstract}

Key words: anterior cruciate ligament, femoral epicondyles, ligament graft, reconstruction 


\section{Introduction}

Anterior cruciate ligament (ACL) injuries are very common, ${ }^{1,2}$ especially in sport activities that put high demand on the ACL, such as soccer. ${ }^{3}$ The knee is a lowplaced, mobile and weight-bearing joint that functions as a fulcrum between the femur and tibia. ${ }^{4,5}$ The stability of the knee depends almost entirely on the ligaments and muscles surrounding the knee joint. The mobility of this joint makes it prone to injuries, especially during rotation movements. ${ }^{4}$ The ACL is particularly at risk as it prevents posterior displacement of the distal femur on the proximal tibia or anterior tibial translation. However, during strong rotation movements within the knee joint, the ACL can tear. ${ }^{5-9}$ The ACL can also tear when force is exerted anteriorly against the femur with the knee in a semi-flexed position, when hyperextension has occurred, or when the femur and tibia twist in opposite directions. . $^{1,3,4}$

Symptomatic instability of the knee together with a proven ACL tear is an indication for ACL reconstruction. ${ }^{3,10}$ Different treatment options include non-operative interventions, but the preferred method of ensuring future knee stability is

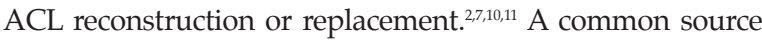
of grafts used for ACL reconstruction is the bone-patellar tendon-bone (BTB) graft, first described by Palmer in 1938.12 This graft is harvested from the middle third of the patellar ligament (PL) in the long axis. ${ }^{713-17}$ This technique was initially explained by Jones in the 1960s. ${ }^{18,19}$ The bundles of the ACL have also been the subject of many research articles and are an important component that should be considered during ACL reconstruction. ${ }^{5,7,920-22}$

Successful graft reconstruction requires knowledge of the morphological characteristics of the PL and the ACL, as well as of the relationship between these two ligaments. Knowledge of the length and width of the intra-articular ACL may play an important role in the preparation of the graft. ${ }^{5}$ An incorrect graft can lead to knee instability, reduced range of motion, failure of implant fixation, or even osteoarthritis in the knee joint. ${ }^{28,10,13}$ The ability to determine the optimal length of the graft ligament required for replacement of the ACL in advance could facilitate more efficient pre-operative planning.

Determining the length and width of the ACL and the length of the PL was this study's first aim. The second was to establish whether it was possible to accurately predict the ACL length when the maximum femoral epicondylar width (FECW) of the distal femur, height of the individual, PL length and ACL width were known. This prediction could possibly allow the pre-operative estimation of the length of the ACL and give an indication of the graft length required to restore the normal anatomy of the ruptured ACL.

\section{Materials and methods}

Ninety-one formalin-fixed adult cadavers with a mean age of 60.4 years (range 21-96 years) were studied. The majority of the sample was male $(71.4 \%)$ and white $(60.4 \%)$.
The average height of the sample was $1.69 \mathrm{~m}$ (range $1.51-1.87 \mathrm{~m}$ ). Only right knees were used to ensure uniformity of the results. The knees of 25 cadavers were excluded (therefore 66 included) because of previous knee surgery, the presence of knee pathology, or damage to the relevant ligaments.

The cadavers were obtained from the Department of Anatomy at the University of Pretoria and the University of Limpopo, Medunsa campus. Ethical clearance (Ethics reference number 151/2013) was obtained from the Research Ethics Committee, Faculty of Health Sciences, University of Pretoria. All cadaveric material used in this study was handled in accordance with the requirements of the South African National Health Act, Act 61of 2003. From the researched literature ${ }^{13}$ it had been concluded that sex, age and weight differences had no influence on the length of the $\mathrm{ACL}$, and, as these demographic features were not considered to affect the study outcomes, they were not researched further.

The cadavers were placed in a supine position with the right leg raised and the knee stabilised at $90^{\circ}$ flexion. The PL was exposed by reflecting the skin and overlying soft tissue. The length of the PL was measured at its midpoint from the most inferior aspect of the patella $(\alpha)$ to the superior aspect of the tibial tuberosity $(\beta)$ (Figure 1). ${ }^{16,23}$ This measurement represented the maximum available length of the tendinous portion of the PL graft for ACL reconstruction.

After the PL length was measured, the ACL was revealed by transecting the attachment of the quadriceps femoris muscle to the patella. The patella and PL were reflected inferiorly (Figure 2).

In situ measurements (length and width) of the ACL were taken. The width was measured at the centre of the ligament (Figure 3a). The measurement of the ACL length (Figure 3b) was performed blindly by exploring the proximal

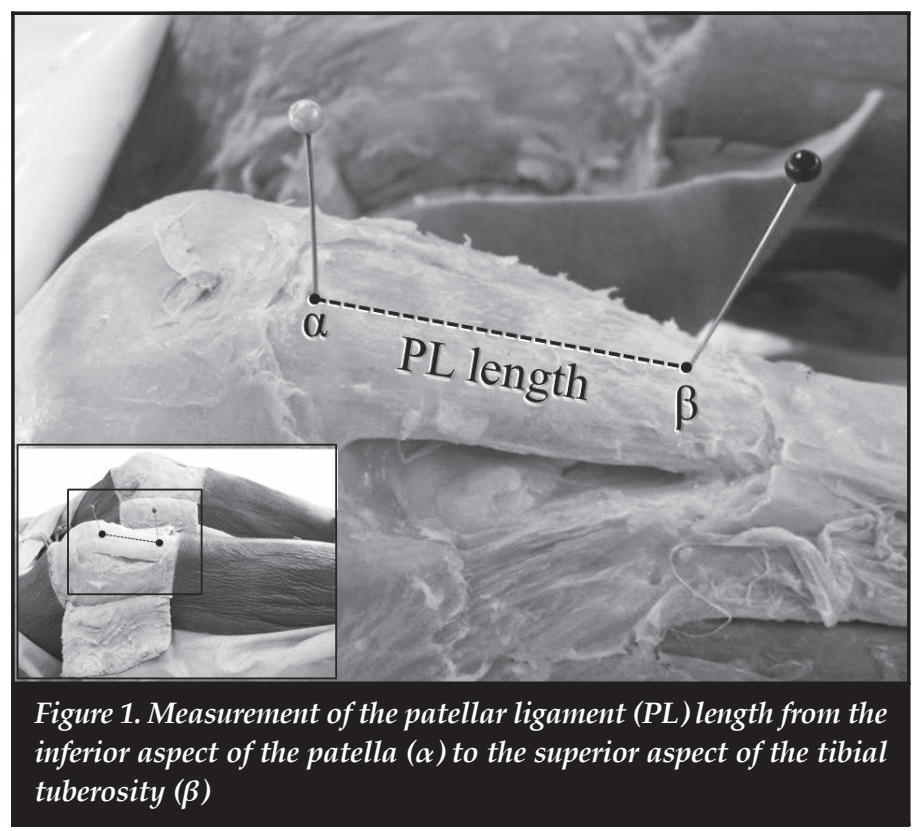



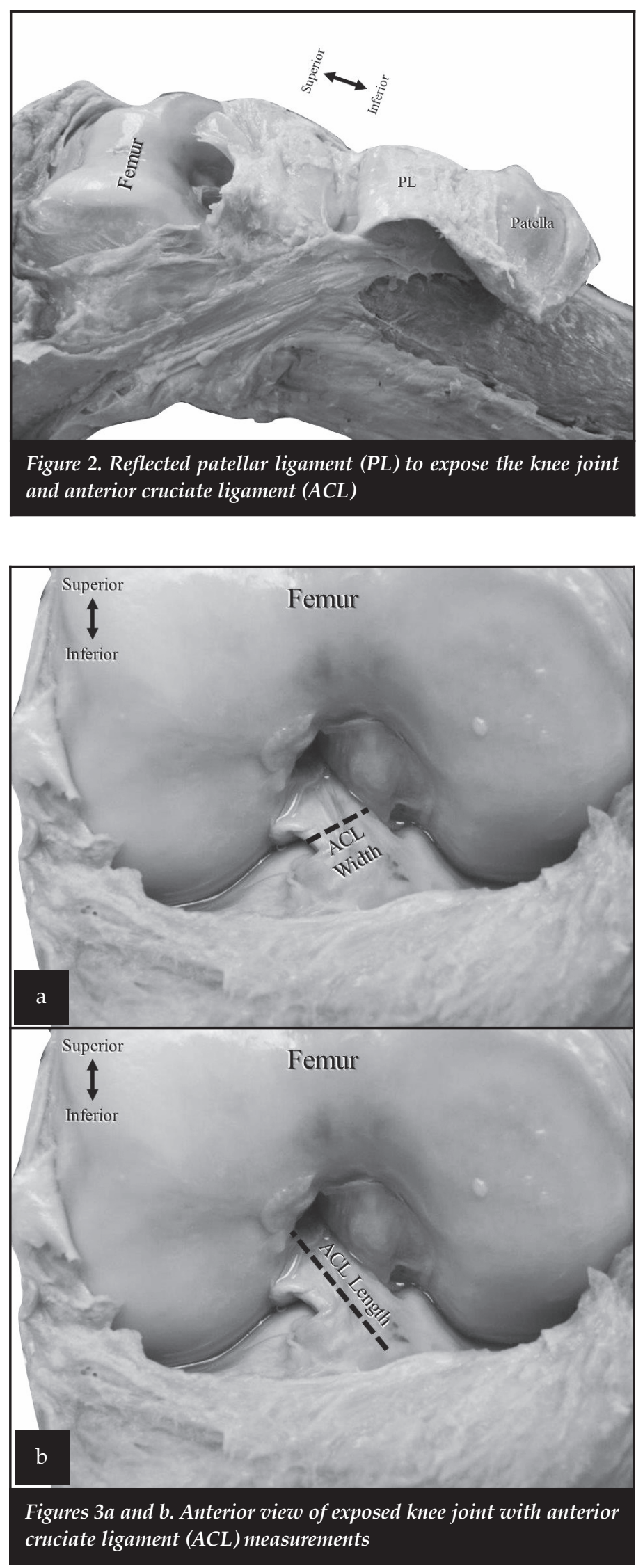

attachment site with a probe until resistance from the femoral attachment site limited further progress. The length of the probe between the femoral attachment site and the visible tibial attachment site of the ACL was used to derive the length of the ACL. All measurements were taken with a mechanical-dial calliper (accuracy $0.01 \mathrm{~mm}$ ).

In order to determine if the ACL length could be accurately predicted by measurements on several independent variables, four potential predictors were selected. A possible correlation was investigated between the ACL length (dependent variable) and the height of the individual, maximum FECW of the distal femur, PL length and ACL width (independent variables). The height of the cadavers was available from the cadaver records.

The soft tissue at the most medial and most lateral points of the femoral epicondyles was removed. The distance between the most medial and most lateral points of the femoral epicondyles was measured (Figure 4). Patellar ligament length and ACL width were determined as part of the first aim of this study.

\section{Statistical analysis}

First, box plots were used to determine if the data collected for each variable were symmetrically distributed. Simple descriptive statistics were conducted on all variables (mean, standard deviation [SD], minimum and maximum values). Statistical analyses were performed using the Pearson's correlation coefficient test to calculate associations between the dependent variable and each of the four independent variables. Finally, a linear regression model was developed using SAS 9.3 for Windows (Copyright (c) 2002-2010 by SAS Institute Inc., Cary, NC, USA) with ACL length as the dependent variable. Height, FECW, PL length and ACL width were the potential independent predictors.

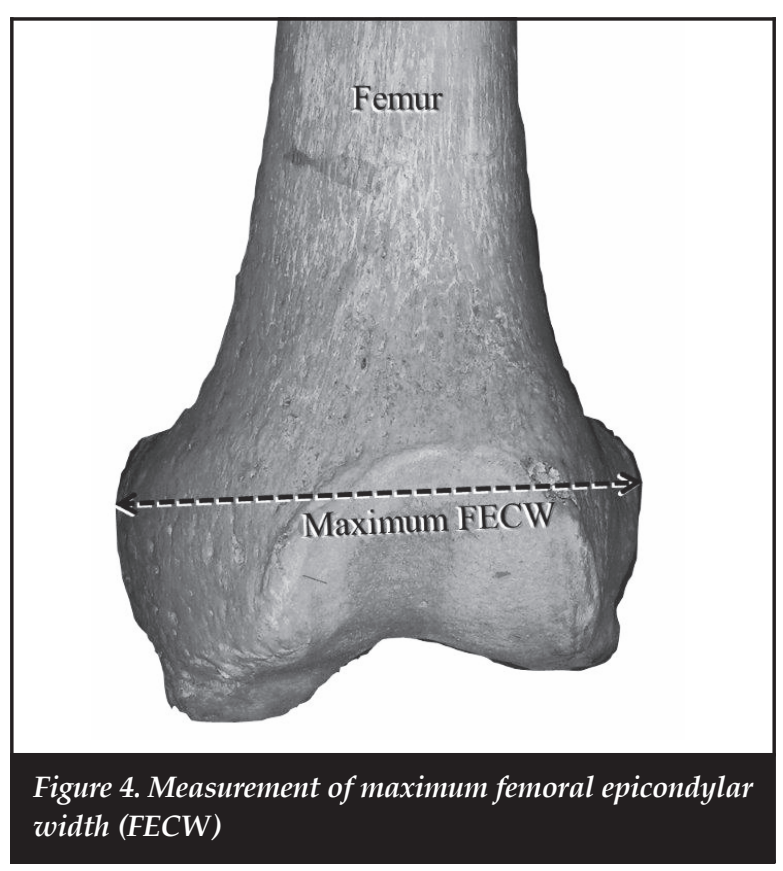




\section{Results}

All data were symmetrically distributed. The descriptive analysis results are shown in Table I. The Pearson's correlation coefficient results can be seen in Table II. The Pearson's correlation coefficient $r$-value was determined to suggest which of the four independent variables demonstrated a significant positive or negative linear relationship with the dependent variable, ACL length. (Table II). If the $p$-value of the Pearson's correlation coefficient test was $p<0.05$, it was considered as a statistically significant correlation.

Statistical inference followed after the completion of the descriptive statistics in order to predict ACL length. By means of backward elimination using a multiple regression model, it was observed that both height and FECW had a statistically significant correlation to ACL length. However, FECW was a more reliable predictor for estimating ACL length than height ( $r=0.36$ against $r=0.31$, respectively). On the basis of this estimation, no additional variables were used to compile an equation for preoperative ligament length estimation.

A linear regression formula was developed for predicting ACL length and, therefore, optimum final graft length to re-establish the intra-articular length of the torn ACL. The following equation (Equation 1) can be used to predict ACL length by measuring the maximum FECW:

$$
\text { ACL length }=\mathbf{0 . 2 5}(\text { FECW })+\mathbf{1 1 . 1 8}
$$

where $\mathrm{ACL}=$ anterior cruciate ligament;

FECW=femoral epicondylar width

\section{Discussion}

The mismatch of grafts can be minimised by more accurate prediction of ACL intra-articular length and the required graft length for ACL reconstruction. The first aim of this study was to determine the morphology of the ACL and PL. This study has shown that the mean intra-articular ACL length of this sample was $32.4 \mathrm{~mm}$, with a range between 22.9 and $45.1 \mathrm{~mm}$. The literature has shown different results for the mean length of the ACL, namely: $20 \mathrm{~mm},{ }^{24} 31 \mathrm{~mm},{ }^{25} 32 \mathrm{~mm},{ }^{5,79} 38 \mathrm{~mm},{ }^{8}$ and $39 \mathrm{~mm} .^{26}$ The ACL length has exhibited some variability, with reported ranges of 20-25 mm, ${ }^{13} 22-41 \mathrm{~mm},{ }^{9} 22-44 \mathrm{~mm},{ }^{7} 25-35 \mathrm{~mm},{ }^{25}$ and $37-41 \mathrm{~mm} .{ }^{26}$ The mean width of the ACL calculated in the current study was $8.2 \mathrm{~mm}$, ranging from $5.1-13.7 \mathrm{~mm}$. This measurement differs slightly from the range of 7-12 $\mathrm{mm}$ as determined by Bicer et al., Zantop et al. ${ }^{5}$ and Odensten and Gillquist. ${ }^{25}$ Previous authors found the ACL to have a mean width of $10 \mathrm{~mm}^{25}$ and $11 \mathrm{~mm} .^{8}$

The PL mean length of this sample was $45.7 \mathrm{~mm}$, ranging between $31.6 \mathrm{~mm}$ and $59.2 \mathrm{~mm}$. These measurements were similar to results from previous studies: Brown et al..$^{13}$ recorded a range of $45-50 \mathrm{~mm}$ and Denti et al. ${ }^{24}$ a mean length of $45.5 \mathrm{~mm}$. On average, the PL is $14 \mathrm{~mm}$ longer than the ACL in this study and is therefore sufficient in length to allow effective fixation of the graft.

\begin{tabular}{|c|c|c|c|}
\hline & \multicolumn{3}{|c|}{ Variables } \\
\hline & $\begin{array}{l}\text { PL length } \\
(\mathrm{mm})\end{array}$ & $\begin{array}{l}\text { ACL length } \\
(\mathrm{mm})\end{array}$ & $\begin{array}{l}\text { ACL width } \\
\text { (mm) }\end{array}$ \\
\hline Mean & 45.66 & 32.44 & 8.23 \\
\hline SD & 5.71 & 4.06 & 1.96 \\
\hline Minimum & 31.56 & 22.90 & 5.10 \\
\hline Maximum & 59.17 & 45.10 & 13.74 \\
\hline
\end{tabular}

Table II: Correlation matrix to indicate associations between the dependent (ACL length) and independent variables

\begin{tabular}{|c|c|c|}
\hline \multirow{2}{*}{$\begin{array}{c}\text { Independent } \\
\text { variables }\end{array}$} & \multicolumn{2}{|c|}{ ACL length } \\
\hline & $p$-value & $r$-value \\
\hline Height & $.01^{\mathrm{a}}$ & 0.31 \\
\hline PL length & 0.92 & 0.01 \\
\hline FECW & $0.00^{\mathrm{a}}$ & 0.36 \\
\hline ACL width & 0.26 & 0.14 \\
\hline
\end{tabular}

Variation in PL length could explain the occurrence of graft mismatch found with ACL reconstructive surgery. Lastly, the slight differences between both the ACL and PL measurements from this sample and other reported measurements could be attributed to the respective population differences of the samples studies. The comparisons were made between the current sample (South African), an Italian sample $\mathrm{e}^{24}$ and a North American sample. ${ }^{13}$ The measuring technique used could also account for the dissimilarities found among the studies referred to by Brown et al. ${ }^{13}$ and Denti et al. ${ }^{24}$

ACL length and PL length demonstrated no significant statistical correlation $(p=0.92)$, as was the case between ACL length and ACL width ( $p=0.26)$. The significant correlation between ACL length and height $(p=0.01)$ was not unexpected. Brown et al. ${ }^{13}$ in 2007 found a strong correlation on a large magnetic resonance imaging (MRI) study sample consisting of 414 knees, and concluded that patient height can predict the required length of the BTB graft used for ACL reconstruction. In contrast, Denti and Coworkers, ${ }^{24}$ using 50 reconstructed and nine cadaver knees, were unable to confirm this relationship between ACL length and patient height. ACL length and FECW revealed a significant correlation of $p<0.01$ in this study. 
It was also statistically determined that FECW could account for the other three independent variables in predicting ACL length as FECW had a strong correlation with all other variables. Femoral epicondylar width was found to be the most reliable predictor of ACL length $(r=0.36)$ as opposed to height, which had an $r$-value $=0.31$. A significant model was developed for the estimation of ACL length when FECW is known. The $\mathrm{R}^{2}$-value of 0.13 indicated that $13 \%$ of variation found in ACL length (among the cadavers) could be accounted for by Equation 1. Therefore, measuring the FECW of the patient might allow for pre-operative estimation of the length of the ACL by using the previously mentioned linear regression formula. These values could then be utilised to predict the required graft length to replace the torn or ruptured ACL.

Maximum FECW was used in the current study to correlate with ACL length. Patient height is often unknown and FECW is a practical measurement, as it is commonly available on X-ray and MRI. ${ }^{13,24}$ In this sample, FECW has also proven to be a slightly more reliable predictor than height for ACL length estimation. When comparing ACL length and FECW, a definite positive correlation between the measurements $(p<0.05)$ was noticed. However, the low $\mathrm{R}^{2}$-value of the linear regression indicates that in the South African cadaver sample examined in the current study, the FECW cannot be the sole predictor of ACL length. Preoperative mismatch of the graft length could occur if the FECW is measured without the incorporation of additional imaging modalities. Intra-operative measurements may also assist to determine ACL length and therefore the required graft length.

The weak positive correlation observed for predicting ACL length using the maximum FECW could be explained by remnants of soft tissue covering the epicondyles after dissection, which may have led to inaccurate measurement of the maximum FECW. Dissection of the ACL was also problematic because the ligament coursed diagonally within the knee joint. The measurement was therefore taken blindly, which could have resulted in inaccurate measurements of the true ACL length.

Utilising imaging modalities could allow clinicians a greater degree of accuracy in estimating ACL length from measuring the FECW of the patient. Future studies could therefore be designed to investigate whether the correlation between the ACL length and the FECW could be improved when measured on MRIs. These findings should be verified in the clinical setting.

\section{Conclusion}

The anatomy of the ACL and PL of this South African cadaver sample compared favourably with results reported in previous studies conducted on other population groups. Similar to some of these studies, a correlation was found between the intra-articular ACL length and the height of the cadaver. It was also found that the maximum FECW of a patient can predict the length of the intra-articular ACL more reliably than the height of the patient can. Using FECW as a possible predictor provides an additional method for estimating the pre-operative length of the graft required for ACL reconstruction and minimising the chance of graft mismatch.

\section{Acknowledgements}

The financial assistance of the Research Development Programme (RDP) toward this research is hereby acknowledged. Opinions expressed and conclusions arrived at are those of the authors and are not necessarily attributed to the RDP. Mrs Joyce C Jordaan is greatly thanked for her assistance with the conduction of statistical analyses. Barbara English of the research office of the University of Pretoria's Faculty of Health Sciences is thanked for her language editing. Medical editor, Ms Theanette Mulder, of the Support School of Medicine of the University of Free State is deeply thanked. Finally, the authors kindly thank all the body donors without whom this research would not have been possible.

\section{Compliance with ethics guidelines}

\section{- Conflict of interest}

The enclosed manuscript has been read and approved by all authors. The authors, Mrs Van Zyl and Drs Van Schoor, Du Toit and Louw, have no conflict of interest to declare.

- Benefits

No benefits of any form have been received from a commercial party related directly or indirectly to the subject of this article.

- Ethics statement

Ethical clearance (Ethics reference number 151/2013) was obtained from the Research Ethics Committee, Faculty of Health Sciences, University of Pretoria. All cadaveric material used in this study was handled in accordance with the requirements of the South African National Health Act, Act 61of 2003.

\section{References}

1. Boden BP, Griffin LY, Garrett WE Jr. Etiology and prevention of noncontact ACL injury. Phys Sportsmed 2000;28(4):53-60.

2. Wipfler B, Donner S, Zechmann CM, Springer J, Siebold R, Paessler HH. Anterior cruciate ligament reconstruction using patellar tendon versus hamstring tendon: a prospective comparative study with 9-year follow-up. Arthroscopy 2011;27(5):653-65.

3. Yu B, Garrett WE. Mechanisms of non-contact ACL injuries. Br J Sports Med 2007 Aug;41:Suppl 1:i47-i51.

4. Moore KL, Dalley AF, Agur AMR. Clinically oriented anatomy. 6th ed. Philadelphia: Lippincott Williams \& Wilkins; 2009. p. 639-63.

5. Zantop T, Petersen W, Fu FH. Anatomy of the anterior cruciate ligament. Oper Tech Orthop 2005;15(1):20-8.

6. Amis AA, Bull AMJ, Lie DTT. Biomechanics of rotational instability and anatomic anterior cruciate ligament reconstruction. Oper Tech Orthop 2005;15(1):29-35. 
7. Bicer EK, Lustig S, Servien E, Selmi TA, Neyret P. Current knowledge in the anatomy of the human anterior cruciate ligament. Knee Surg Sports Traumatol Arthrosc 2010;18(8):107584.

8. Markatos K, Kaseta MK, Lallos SN, Korres DS, Efstathopoulos $\mathrm{N}$. The anatomy of the ACL and its importance in ACL reconstruction. Eur J Orthop Surg Traumatol 2013;23(7):747-52.

9. Petersen W, Zantop T. Anatomy of the anterior cruciate ligament with regard to its two bundles. Clin Orthop Relat Res 2007 Jan;454:35-47.

10. McCulloch PC, Lattermann C, Boland AL, Bach BR Jr. An illustrated history of anterior cruciate ligament surgery. J Knee Surg 2007;20(2):95-104.

11. Miller MD. Knee. In: DeLee JC, Drez D Jr, Miller MD, editors. DeLee $\mathcal{E}$ Drez's Orthopaedic Sports Medicine. 3rd ed. Philadelphia: Elsevier Saunder; 2010. p. 1579-1609.

12. Palmer I. On the injuries to the ligaments of the knee joint. A clinical study. Acta Chir Scand 1938;Suppl 53:1-28.

13. Brown JA, Brophy RH, Franco J, Marquand A, Solomon TC, Wantanabe D, Mandelbaum BR. Avoiding allograft length mismatch during anterior cruciate ligament reconstruction: patient height as an indicator of appropriate graft length. Am J Sports Med 2007;35(6):986-89.

14. Cheung SC, Allen CR, Gallo RA, Ma CB, Feeley BT. Patients' attitudes and factors in their selection of grafts for anterior cruciate ligament reconstruction. Knee 2012;19(1):49-54.

15. Gerhard P, Bolt R, Dück K, Mayer R, Friederich NF, Hirschmann MT. Long-term results of arthroscopically assisted anatomical single-bundle anterior cruciate ligament reconstruction using patellar tendon autograft: are there any predictors for the development of osteoarthritis? Knee Surg Sports Traumatol Arthrosc 2013;21(4):957-64.

16. Miller MD. Knee and lower leg. In: Miller MD, Chhabra AB, Hurwitz S, Mihalko WM, Shen FH, editors. Orthopaedic surgical approaches. Philadelphia: Elsevier Saunders; 2008. p. 423-90.

17. Schmidt-Wiethoff R, Dargel J, Gerstner M, Schneider T, Koebke J. Bone plug length and loading angle determine the primary stability of patellar tendon-bone grafts in press-fit ACL reconstruction. Knee Surg Sports Traumatol Arthrosc 2006;14(2):108-11.
18. Jones KG. Reconstruction of the anterior cruciate ligament. A technique using the central one-third of the patellar ligament. J Bone Joint Surg Am 1963;45:925-32.

19. Jones KG. Reconstruction of the anterior cruciate ligament using the central one-third of the patellar ligament. A followup report. J Bone Joint Surg Am 1970;52(7):1302-1308.

20. Amis AA, Dawkins GP. Functional anatomy of the anterior cruciate ligament. Fibre bundle actions related to ligament replacements and injuries. J Bone Joint Surg Br 1991;73(2):26067.

21. Beasley LS, Weiland DE, Vidal AF, Chhabra A, Herzka AS, Feng MT, West RV. Anterior cruciate ligament reconstruction: a literature review of the anatomy, biomechanics, surgical considerations, and clinical outcomes. Oper Tech Orthop 2005;15(1):5-19.

22. Tantisricharoenkul G, Linde-Rosen M, Araujo P, Zhou J, Smolinski P, Fu FH. Anterior cruciate ligament: an anatomical exploration in humans and in a selection of animal species. Knee Surg Sports Traumatol Arthrosc 2014;22(5):961-71.

23. Miles J, Carrington R. Soft tissue surgery of the knee. In: Briggs T, Miles J, Aston W, editors. Operative Orthopaedics: the Stanmore Guide. London: Hodder Arnold; 2010. p. 200-17.

24. Denti M, Bigoni M, Randelli P, Monteleone M, Cevenini A, Ghezzi A, Schiavone Panni A, Trevisan C. Graft-tunnel mismatch in endoscopic anterior cruciate ligament reconstruction. Intraoperative and cadaver measurement of the intra-articular graft length and the length of the patellar tendon. Knee Surg Sports Traumatol Arthrosc 1998;6(3):165-68.

25. Odensten M, Gillquist J. Functional anatomy of the anterior cruciate ligament and a rationale for reconstruction. J Bone Joint Surg Am 1985;67(2):257-62.

26. Kennedy JC, Weinberg HW, Wilson AS. The anatomy and function of the anterior cruciate ligament. As determined by clinical and morphological studies. J Bone Joint Surg Am 1974;56(2):223-35.

This article is also available online on the SAOA website (www.saoa.org.za) and the SciELO website (www.scielo.org.za). Follow the directions on the Contents page of this journal to access it. 